\title{
Leitura Fragmentária: Premissas e Implicações
}

\section{Fragmentary Reading: Premises and Implications}

DOI: $10.46814 / \operatorname{lajdv3n1-016}$

Recebimento dos originais: 30/10/2020

Aceitação para publicação: 23/12/2020

\section{Jean Pierre Chauvin}

Professor Doutor, Departamento de Jornalismo e Editoração, Escola de Comunicações e Artes da

Universidade de São Paulo

E-mail: tupiano@usp.br

\section{RESUMO}

Este trabalho contém uma série de reflexões concernentes ao ato da leitura, como item fundamental para a mediação do conhecimento, na relação entre os diferentes papéis representados social e culturalmente por alunos e professores. Ele se liga diretamente a experiências vinculadas (não exclusivamente) à sala de aula.

Palavras-Chave: Leitura, Ensino, Mediação.

\begin{abstract}
This work contains some reflections about lecture's act, conceived like an essential iten in a way to intermediate the knowledge, observating the relationship between the different roles social and culturally represented by students and teachers. He is directly attached to the experiences on (and beyond) the classroom.
\end{abstract}

Keywords: Lecture, Learning, Mediation.

\section{INTRODUÇÃO}

\begin{abstract}
Em sociedade que exclui dois terços de sua população e que impõe ainda profundas insjustiças à grande parte do terço para o qual funciona, é urgente que a questão da leitura e da escrita seja vista enfaticamente sob o ângulo da luta política a que a compreensão científica do problema traz sua colaboração (FREIRE, 2011, p. 17).
\end{abstract}

Comecemos por um truísmo: a palavra preside a constituição do sujeito. Já deveríamos ter aprendido com Sigmund Freud que ela pode ter efeito inclusive curativo, sendo um recurso fundamental na terapêutica indicada para pessoas em diferentes graus de neurose: “O tratamento analítico requer trabalho árduo do médido e do paciente, um trabalho dedicado à anulação das resistências internas.” (FREUD, 2014, p. 597)

Sabemos também, pelo menos desde Jacques Lacan, que a palavra é que faz a mediação entre o eu e o sujeito ciente de seu lugar em determinados espaços e tempo histórico: "Quando o homem 
esquece que é portador da fala, ele já não fala. É efetivamente o que acontece: a maioria das pessoas não fala, elas repetem, não é exatamente a mesma coisa. Quando o homem já não fala, ele é falado" (LACAN, 2008, p. 61).

Relembramos, com Michel Foucault, que o discurso suscita diferentes consequências, em acordo com quem fala, de onde fala, como fala e para quem fala: "Em uma sociedade como a nossa, conhecemos, é certo, procedimentos de exclusão. O mais evidente, o mais familiar também, é a interdição" (FOUCAULT, 2009, p. 9 - grifos do autor).

O primeiro pressuposto desta intervenção diz respeito às diferentes formas de se estimular a leitura. Sob a perspectiva adotada nesse trabalho, o ato de ler combinaria o impulso (desejo) à formação (artifício) do leitor. Ou seja, a espontaneidade estaria em diálogo com a consciência de que ler é um prazeroso exercício de emancipação intelectual.

\section{O PROFESSOR É UMA FALA}

A escola ensina a ler e a gostar de literatura. Alguns aprendem e tornam-se leitores literários. Entretanto, o que quase todos aprendem é o que devem dizer sobre determinados livros e autores, independentemente de seu verdadeiro gosto pessoal (ABREU, 2006, p. 19 - grifos da autora).

Circunscrevamos a atitude da fala, entendendo-a como um complexo ato de linguagem inerente aos homens, mas em particular, ao ofício do professor, observando-se a sua relação com os alunos. Há quase quarenta anos, Roland Barthes afirmara em sua Aula que esse profissional tem duas tarefas fundamentais: a de "pesquisar e falar" (BARTHES, 2007, p. 9). Sob essa ótica, caberia perguntar: qual o papel do aluno?

Levemos em conta essas acepções e poderes concernentes aos atos de fala e dos papéis desempenhados por seus atores. Partamos do pressuposto de que a fala possa tomar parte efetiva na constituição e integração do sujeito. Daí, a interdição do que de afirma pode provocar diversas adversidades para a auto-estima e o trânsito do sujeito em seu percurso.

Nem verborragia, nem mutismo: ambos parecem ser sintomas de descontrole ou desajuste. Quando comenta a postura silenciosa dos homens, sacudidos socialmente e em seu íntimo pelas guerras brutais que sofreram ao longo do século XX, Eduardo Subirats detecta o fato de que: "Há experiências de angústia e terror quese cristalizam nas metáforas do abismo, do nada e da perda de sentido do todo, e que em suas últimas consequências ultrapassam a fronteira do explicável. Experiências de uma realidade na qual as palavras perdem seu significado" (SUBIRATS, 2010, p. 61).

O dado cultural caminha em paralelo à capacidade de representar os eventos traumáticos. Acresce que, em favor com ou avessa aos signos da violência, desde a invenção da escrita a fala nunca 
mais esteve só. Ela passou a ser uma dentre as formas verbais de representação, e também de resistência, com que o homem se comunica, em tese solidariamente, com os demais - com maiores ou menores graus de divergência.

Ora, se a fala pede um bom ouvinte, a leitura demanda o leitor de qualidade: obviedade que é preciso recordar. Nas instituições de ensino, o trabalho direto a partir dos textos sugere que a interlocução entre alunos, professores e escritores levasse em conta a palavra impressa como um dos efetivos fatores de mediação, em benefício do processo educativo.

No entanto, a despeito do truísmo dessas afirmações, o fato incontestável é que a maior parte de nossos alunos lê pouco ou mal. Ou seja, a maioria dos estudantes descumpre os pactos supostamente firmados com seu professor, por mais tirânica ou democrática que seja a proposta do docente. Isso acontece por mais agradáveis, úteis e relevantes que sejam os textos sugeridos pelo professor.

Se o pacto pedagógico não se estabelecer, a razão de ser da aula estará grandemente comprometida, pois ela supõe um ato mútuo de respeito, solidariedade e confiança. Os encontros em sala tornam-se marcados pela incosistência e fingimento. Assim, compreende-se a natural sensação de que o outro lado não seja nossa contraparte.

\section{FORMAS DE (IN)VALIDAÇÃO}

Penso que cada palavra necessita sempre pelo menos outra que a ajude a explicar-se (SARAMAGO, 2009, p. 138).

É curioso que o próprio termo "professor", que nos definiria como cidadãos honrados durante muito tempo, esteja sendo empregado com sentido e sinal negativo por alguns de meus colegas, como se a palavra não contivesse em si mesma os valores intrínsecos de nossa profissão.

No ensino dito superior, alguns pares fazem questão de agregar outras chancelas socioculturais ao que melhor os nomeie. Denominar-se "professor" soa algo menor e menos importante que “Professor Doutor". Mas há palavras consideradas ainda mais pejorativas: “educador” é um desses conceitos vistos com maus olhos por uma parcela de gestores e professores que rejeitam o trabalho em sala de aula e, em sua concepção tecnocrática, adoecem determinadas organizações.

Como é de se imaginar, a denominação exigida por alguns indivíduos é um velho problema de nossa história cultural. A questão foi denunciada por Lima Barreto em uma de suas divertidíssimas crônicas satíricas de Os Bruzundangas: "O título - doutor - anteposto ao nome, tem na Bruzundanga o efeito do - dom - em terras de Espanha. Mesmo no Exército, ele soa em todo o seu prestígio nobiliárquico" (BARRETO, 1998, p. 42). 
A questão é antiga e séria. Diz muito sobre nossa cultura "bacharelesca", para tomar de empréstimo um termo de Sérgio Buarque de Holanda (1995). Fachada versus essência; passividade e tédio versus vida; leitura diagonal em lugar da leitura atenta do texto. Não chegamos ao microtexto também porque se passou a desconfiar do caráter do outro; da serventia em se saber analisar e interpretar palavras arranjadas de modo artístico ou reflexivo.

Sob a lógica exclusivista do mercado, com frequência o texto é enxergado como obstáculo à otimização de demais atividades, em prol da economia de tempo. São comuns os discursos que reiteram a utilização de livros em linguagens atualizadas e facilitadas, que vão se adaptando ao repertório cada vez mais restrito daqueles que menos leem.

Em lugar de desafiar os leitores, o texto os atira para as lonjuras do hermetismo, ainda que o leitor virtual sequer tenha se aproximado da forma escrita, da matéria livro, do suporte (impresso ou digital). Talvez alguns alunos vejam nos pedidos de seus professores a manifestação de um poder de que discordam e a que se contrapõem. “Quem é ele para dizer o que devo ou preciso ler”? “Qual a efetiva vantagem de me preparar para essa aula, considerando as demais atividades do curso e os fatos urgentes de minha vida"?

Alguns desejariam atribuir as tristes estatísticas qualitativas ao apelo narcisista e magnético das novas mídias - aquelas que nasceram juntamente com a internet e se aprimoraram com o discurso fragmentário e a supervalorização do imagético. Como parte dessa parcela, alguns estudantes mostramse gradativamente menos atentos aos conteúdos curriculares, orientados que estão pelo mundo circunscrito das telas e micro-telas, multi, maxi e self-informativas.

Um contra-argumento a essa forma de pensar reside em outro truísmo. Ora, sempre houve apelos técnicos ou tecnológicos, ao longo dos séculos. Seria, efetivamente, o caso de refundar as teorias educacionais a cada descoberta tecnológica e estabelecer uma nova práxis, um novo caminho de duas mãos entre a teoria e a prática, a começar pelo âmbito da sala de aula?

Ou seria o momento de transferir de volta para o aluno a parte mínima que lhe cabe? Qual seja, julgá-lo como um ser pensante e ativo, preparado para o evento-aula, fazendo do texto, da imagem, da leitura prévia autênticos materiais para a efetiva mediação do saber e da reflexão com seus colegas e professores?

Luiz Marcuschi (2005) aborda a assunção do discurso digital sob uma ótica algo otimista, a meu ver, pois parece se orientar pela produção textual em várias modalidades, como se as formas se equiparassem. Para ele, precisamos acelerar mecanismos e novos modos de reclassificar e produzir os "gêneros emergentes" do discurso.

De fato. 
Mas, o que dizer da qualidade intrínseca dos textos, concebidos para veículos, suportes e públicos diversos? O que pensar das evidentes diferenças estilísticas, sintáticas e semânticas nos diversos tipos, modos e formatos textuais, produzidos para além do impresso?

Não se pode desprezar que há diferenças entre os "níveis de linguagem” e que elas constituem a heterogeneidade das pessoas e seus modos de fala e apropriação dos gêneros discursivos. Negar a diferença é negar o óbvio e servir ao ecletismo. Em situações de assimetria social, cultural e econômica, frequentemente isso nos leva a nivelar rasteiramente o que tem características e procedimentos próprios.

Bastaria percorrer as milhares de referências, de Aristóteles, quatro séculos antes de Cristo, a Francis Vanoye, na década de 1970, para recordar a lição milenar de que o texto trata de um assunto, de acordo com determinado estilo e gênero, conforme o efeito que se pretenda produzir em nosso auditório, seja ele particular ou universal (PERELMAN, 1997).

\section{O DISCURSO AUTO-DESTRUTIVO}

Posta pela divisão social do trabalho do lado "improdutivo", na sociedade capitalista a cultura deverá, de algum modo, compensar essa "improdutividade". A compensação, efetuada de várias maneiras, resulta sempre no mesmo, ou sea, na instrumentalização da produção cultural. (CHAUÍ, 2001, p. 58-59)

Afora a reconhecida desunião e falta de solidariedade do professorado, na esfera pública e privada, nas séries do Ensino fundamental, médio e superior, há um outro discurso predominante entre nós que diz e repete o chavão ideológico de que a responsabilidade do fracasso escolar (do alunovítima) é atribuição quase exclusiva de quem educa ou facilita o conhecimento.

Entre a costumeira culpabilização do professor, contraparte da mesmíssima ideologia que inocenta o fator clientelista (em prol do aluno e dos gestores), uma das queixas mais ouvidas da parte dos docentes, especialmente em nossos dias, reside no desinteresse que boa parte dos estudantes sequer disfarça - antes, ostenta - ao ignorar ou desprezar o contato com as múltiplas formas de conhecimento na sala de aula.

A confusão de papéis e poderes cresce com um tédio de caras brandas, discursos amenos e previsíveis e vozes afetadas, alteradas. O gosto da polêmica persiste e é avassalador, pois combina-se à falsa necessidade (criada pela lógica da produtividade) de fazer algo o tempo inteiro, nem que seja contrapor-se, sem argumentos consistentes, aos pressupostos do outro.

Ora, o acúmulo de atividades - nem sempre relacionadas à leitura e à anotação de textos talvez leve o estudante mediano a priorizar as tarefas mais "práticas" e questionar a validade, ou mesmo a utilidade da aula como matriz de sua aprendizagem, ainda mais se ele levar em conta exclusivamente 
a ótica propedêutica do ensino, sob a conhecida fórmula do etapismo: crescer, estudar, trabalhar, enriquecer.

Tendo em vista que o espaço da sala de aula pressupõe a existência de diferentes atores e sua desejável e necessária interlocução; que um ensino democrático, e preferencialmente libertário, demanda que as partes cumpram com as suas atribuições pessoais, profissionais e acadêmicas, caberia a afirmação de que nem todos aqueles que questionam a qualidade, a competência ou a didática do professor teriam cacife, ética ou bagagem intelectual para fazê-lo.

\section{DA LEITURA PARA A ESCRITA}

Antropologicamente falando, sabe-se que a escrita nasceu antes da leitura. A "representação semiótica" da fala correspondia à necessidade de se fixar registros relacionados às descrições e experiências vivenciadas. Em relação à escrita, Émile Benveniste lembrava que: "É o escrever que foi $\mathrm{o}$ ato fundador. Pode-se dizer que esse ato transformou todo o perfil das civilizações, que foi o instrumento da revolução mais profunda por que passou a humanidade depois do fogo". (BENVENISTE, 2014, p. 167)

Mas há pelo menos uma grande diferença entre o que o ser humano faz hoje e o modo como o homem representava seus atos há milhares de anos. A inscrição de desenhos, símbolos e letras nas cavernas atendia a uma demanda de transcrever as experiências do vivido. A questão que se faz é: terão as pessoas de hoje o mesmo impulso? Sentirão elas a mesma compulsão por escrever?

Fábio Lucas parece ter localizado alguns dentre os paradoxos de nosso tempo: mais se escreve do que se lê, afinal "A vocação narcísea se postou no horizonte. Coincidentemente com o momento em que o sentido da vida é buscado em procedimentos mágicos ou em técnicas de auto-ajuda" (LUCAS, 2001, p. 14). Gilberto Dupas enxerga a questão desta forma:

\footnotetext{
Com crescente influência das lógicas organizacionais, o processo de dessimbolização do mundo passa a ter o economicismo e o tecnocratismo como referências centrais. A crise da civilidade e a intensificação do narcisismo levam, assim, a uma emancipação do indivíduo de todo enquadramento normativo, aversão à esfera pública e sua consequente degradação. A liberdade passa a ser percebida como possível unicamente na esfera privada e gera a progressiva privatização da cidadania (DUPAS, 2003, p. 15).
}

Aceitando tais premissas, podemos nos aproximar do problema de outra forma. A falta de comprometimento do aluno com a leitura em geral estaria relacionada a um mundo potencialmente egótico e egocêntrico, em que as relaçoes tênues foram automatizadas e naturalizadadas pela linguagem fragmentária? Até que ponto a pseudo justificativa "não gosto de ler" não nasceu justamente como reflexo ou contraparte de uma concepção predominantemente pragmática? 
O fato de um curso ter perfil profissionalizante não implica negar a relevância do conjunto de conhecimentos - mais diretamente aplicáveis que outros. A leitura de romances, por exemplo, durou pelo menos três séculos, no Ocidente. Até pouco tempo, ela era considerada uma das atividade de grande importância. Tomava tempo e instruía os leitores, simultaneamente. Favorecia o diálogo respaldado por comentários a respeito do último romance que os interlocutores haviam lido etc.

Com o advento do rádio, da televisão e da internet, a leitura tradicional perdeu parte de seu prestígio cultural e formativo que acumulara durante largo período da história. Para muitas pessoas, o ato de ler passou a ser confundido ora como mera obrigação escolar, ora como passatempo: recurso contra o tédio. $\mathrm{O}$ fragmento enfrenta a integralidade ou, nas palavras de Jean Baudrillard:

No momento em que nossas técnicas e nossas tecnologias criam o instantâneo, embora ligado por continuidades com toda a rede... São fragmentos em rede, se eu posso falar assim! Já não é possível, atualmente, instituir qualquer forma de continuidade, de conjunto ou de totalização, porque ela será imediatamente volatizada pelo próprio sistema (BAUDRILLARD, 2003, p. 39)

Qual o lugar da leitura em uma sociedade de orientação utilitária, com pessoas a viver sob a lógica binária da recompensa? Qual o entre-lugar dos leitores que convivem em meio a um coletivo de passageiros, motoristas e pedestres que passam a maior parte de seu tempo tratando de assuntos de “ordem prática”. Qual o espaço da leitura em meio a uma sociedade que, de modo geral, pressupõe ou aplica o verbo fazer a todas as atividades - com exceção do próprio ato de ler?

\section{LEITURA: PRESSUPOSTO}

Certa vez, em uma aula de "Didática”, na Faculdade de Educação desta Universidade, em 1999, uma de minhas colegas questionou o fato de a professora conduzir suas aulas segundo o método tradicional, algo que, segundo ela, contradizia o pressuposto da disciplina em questão. Ao ser questionada de forma rude e em público, a professora devolveu a pergunta - que a meu ver havia sido formulada de modo injusto e improcedente - com uma ótima provocação à estudante: "Você leu o texto"?

$\mathrm{Na}$ pergunta que dirigiu à aluna, a Professora combinou indignação e inteligência; espontaneidade e estratégia. Certamente habituada a lidar com situações similares, ao longo de sua extensa carreira, a docente reagiu da maneira mais eficaz e eficiente que tinha ao alcance da memória.

Em sua resposta-indagação reside um dos motes que permite consolidar ou abalar a relação entre uns e outros especialmente no espaço sala de aula. Antes de questionar o método empregado pela professora, a aluna poderia ter se respaldado na velha lógica aristotélica do discurso: a premissa vem necessariamente antes do método e este é caminho para o objetivo. 
O fato de a estudante não ter tomado contato com o texto - cuja leitura havia sido agendada pela professora logo na primeira aula, com semanas de antecedência -, mostra que ao deixar de observar uma das premissas fundamentais da disciplina, o seu questionamento sobre a metodologia tornava-se vazio, inconsistente.

A leitura, a reflexão e a realização de tarefas - dentro e fora da sala de aula -, estão dentre os fundamentos do ensino formal. $\mathrm{O}$ fato de o aluno não enfrentar o texto, deixando de saber o que o autor diz; o fato de não apontar suas dúvidas que digam respeito ao vocabulário, às metáforas utilizadas e às referências bibliográficas utilizadas pelo escritor, tudo isso compromete a qualidade da própria aula, por motivos que suponho autoevidentes.

É sintomático que, dentre a minoria que lê, o texto converta-se em um obstáculo, que represente uma perda desnecessária de tempo, contraposta a atividades, em tese mais agradáveis, ligadas ao lazer

ou ao ócio, simplesmente. É curioso que essa parcela do alunado não reconheça que o ato de ler bem é algo compulsório em seu rito de passagem pela escola e pela Graduação.

Ora, obter um certificado que atesta a formação, sem o devido mérito, é um grave ato de corrupção. Corrupção que não diz respeito a hipóteses de teor moral, apenas; ela reside na visão de mundo do sujeito em formação. Ela se orienta bem de acordo com a sua ética menor de atalhar os esforços. E bem sabemos que, frequentemente, apologias em torno da moral e da ética apenas elevam o teor de hipocrisia que determinados seres brandem sem cessar.

\section{CONCLUSÃO (ATO DE LEITURA VERSUS ECONOMIA DE TEMPO)}

Uma vez alfabetizada, a maioria das pessoas se limita à leitura com fins eminentemente pragmáticos, mesmo suspeitando que ler significa inteirar-se do mundo, sendo também uma forma de conquistar autonomia, de deixar de "ler pelos olhos de outrem" (MARTINS, 2007, p. 23).

A concepção de progresso material está no fulcro de uma concepção de vida em que a maximização da produtividade está condicionada à minimização do tempo investido em atividades alheias ao caminho reto do resultado pragmático. Para Roland Barthes, em nosso ato de ler seria preciso "não devorar, não engolir, mas pastar, aparar com minúcia, redescobrir, para ler esses autores de hoje, o lazer das antigas leituras: sermos leitores aristocráticos” (BARTHES, 2006, p. 19)

E no entanto, uma das principais atividades vitimadas, rebaixadas e marginalizadas frente à lógica do tempo é a análise de textos. Muito frequente, a famigerada "leitura diagonal" permite apenas uma coisa ao aluno: enganar a si mesmo, julgando ludibriar o professor e representar um tipo postiço frente aos demais colegas. 
Leituras dessa modalidade tentam ser justificadas pela ideia de que, hoje, nossa medida de tempo é mais veloz e que, portanto, a leitura atenta disputaria o lugar com outros campos de conhecimento e afazeres da vida "prática".

Em convertendo o diploma em trampolim para a pseudo emancipação, a Faculdade tem sido vista não como fim em si mesma, mas como passaporte para outras etapas, agora e enfim lucrativas. Ora, por isso mesmo, se a leitura constitui uma parte do investimento do aluno em sua formação, logo se vê que o pseudo argumento de "faltar tempo" é incoerente, inconsistente.

Ora, não se pode apelar para o relógio, quando determinada atividade (leitura) faz parte da formação, especialmente quando prerrogativa da carreira que o próprio aluno escolheu - seja ele mais ou menos influenciado pelos familiares, seja pelas duras leis do mercado. 


\section{REFERÊNCIAS}

ABREU, M. (2006). Cultura letrada: literatura e leitura. São Paulo: Editora Unesp.

ARISTÓTELES (2012). Retórica a Alexandre. Tradução: Edson Bini. São Paulo: Edipro.

BARTHES, R. (2006). O prazer do texto. 4a ed. Tradução: Jacob Guinsburg. São Paulo: Perspectiva. (2007). Aula. 13a ed. Tradução: Leyla Perrone-Moisés. São Paulo: Cultrix.

BAUDRILLARD, J. (2003). De um fragmento ao outro. Tradução: Guilherme João de Freitas Teixeira. São Paulo: Zouk.

BENVENISTE, É. (2014). Últimas aulas no Collège de France (1968 e 1969). Tradução: Daniel Costa da Silva et al. São Paulo: Editora Unesp.

CHAUÍ, M. (2001). Escritos sobre a Universidade. São Paulo: Editora Unesp.

DUPAS, G. (2003). Tensões contemporâneas entre o público e o privado. São Paulo: Paz e Terra.

FOUCAULT, M. (2009). A ordem do discurso. 18a ed. Tradução: Laura Fraga de Almeida Sampaio. São Paulo: Loyola.

FREIRE, P. (2011). A importância do ator de ler em três artigos que se completam. 51a ed. São Paulo: Cortez.

FREUD, S. (2014). A terapia analítica. In: Conferências introdutórias sobre a psicanálise (1916-1917). Tradução: Sergio Tellaroli. São Paulo: Companhia das Letras.

LIMA BARRETO, A. H. (1988). Os Bruzundangas. Belo Horizonte: Garnier.

LACAN, J. (2008). O mito individual do neurótico. Tradução: Cláudia Berliner. Rio de Janeiro: Zahar.

LUCAS, F. (2001). Literatura e comunicação na era da eletrônica. São Paulo: Cortez.

MARCUSCHI, L. A.; XAVIER, A. C. (Orgs). (2005). Hipertexto e gêneros digitais. 2A ed. Rio de Janeiro: Lucerna.

MARTINS, M. H. (2007). O que é leitura. 19a ed. São Paulo: Brasiliense.

PERELMAN, C. (1997). Retóricas. Tradução: Maria Ermantina Galvão G. Pereira. São Paulo: Martins Fontes.

SARAMAGO, J. (2009). O caderno. São Paulo: Companhia das Letras.

SUBIRATS, E. (2010). A existência sitiada. Tradução: Flávio Coddou. São Paulo: Romano Guerra. VANOYE, F. (2003). Usos da linguagem: problemas e técnicas na produção oral e escrita. 12a ed. São Paulo: Martins Fontes. 